MIRANDA, C.B. et al. Contenção farmacológica em primatas não-humanos com emprego de ketamina e xilazina. Uma revisão bibliográfica. PUBVET, Londrina, V. 5, N. 8, Ed. 155, Art. 1045, 2011.

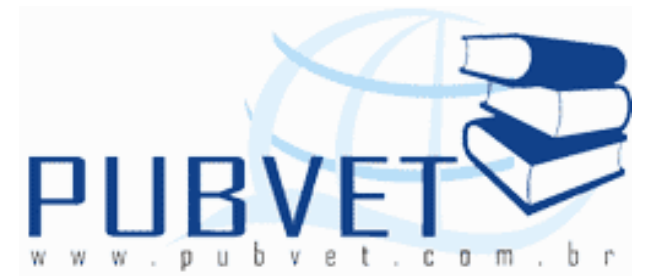

PUBVET, Publicações em Medicina Veterinária e Zootecnia.

\title{
Contenção farmacológica em primatas não-humanos com emprego de ketamina e xilazina. Uma revisão bibliográfica.
}

\footnotetext{
Carina Barbosa de Miranda ${ }^{1}$, Raquel Wolff Cabala ${ }^{2}$, Juan Benito Campos Diz Atan $^{3}$, Lucas Cristo Conilho Macedo Müller ${ }^{4}$, Paulo César Silva ${ }^{5}$, Luiz Alfredo de Magalhães Vivas ${ }^{6}$, Manoel Luiz Ferreira ${ }^{7}$
}

${ }^{1}$ Médica Veterinária Autônoma.

${ }^{2}$ Mestranda em Ciência Animal - Anestesiologia Veterinária da Universidade Estadual de Santa Cruz - Ilhéus - BA.

${ }^{3}$ Graduando em Medicina Veterinária da Universidade Federal Fluminense Niterói - RJ.

${ }^{4}$ Graduando em Medicina da Universidade Federal do Rio de Janeiro - Rio de Janeiro - RJ.

${ }^{5}$ Professor Adjunto II da disciplina de Técnica Operatória da Faculdade de Medicina da Universidade Federal do Rio de Janeiro - Rio de Janeiro - RJ. ${ }^{6}$ Professor Assistente IV da disciplina de Técnica Operatória da Faculdade de Medicina da Universidade Federal do Rio de Janeiro - Rio de Janeiro - RJ.

${ }^{7}$ Professor Assistente do Curso de Medicina Veterinária da Universidade Estadual de Santa Cruz - Ilhéus - BA.

\section{Resumo}

Descreve-se um estudo do uso de cloridrato de ketamina e cloridrato de xilazina na contenção farmacológica de primatas não-humanos em zoológicos e 
MIRANDA, C.B. et al. Contenção farmacológica em primatas não-humanos com emprego de ketamina e xilazina. Uma revisão bibliográfica. PUBVET, Londrina, V. 5, N. 8, Ed. 155, Art. 1045, 2011.

na captura de animais de vida livre. Os efeitos farmacológicos de cada droga e na combinação são investigados em cada sistema fisiológico. Relata-se que a contenção mecânica pode trazer acidentes tanto para os animais quanto para o profissional que lida com estas espécies. A dose de ketamina recomendada na combinação é de $15-20 \mathrm{mg} / \mathrm{Kg}$ para primatas de pequeno porte, de 10 $15 \mathrm{mg} / \mathrm{Kg}$ para primatas de médio porte e de $5-10 \mathrm{mg} / \mathrm{Kg}$ para primatas de grande porte. Xilazina é recomendada na combinação numa dose de 0,1$1,0 \mathrm{mg} / \mathrm{kg}$, independente do porte do animal.

Palavras-chave: Primatas, Contenção, Anestésicos.

\section{Drug retention in non-human primates with employment of ketamine and xylazine. A review.}

\section{Summary}

At this present study, an analysis was made about ketamine chlorhydrate and xylazine chlorhydrate use pharmacological contention of non-human primates in zoological gardens and freelive animal capture. The pharmacological effects of each drug singly and combination are investigated in each physiological system. It was observed that mechanical contention could bring accidents to both animals and professional that handler these species. Ketamine chlorhydrate recommended dose at combination with xylazine is between 15 to $20 \mathrm{mg} / \mathrm{kg}$ to small primates. Xylazine chlorhydrate recommended dose at combination with ketamine is between 0,1 to $1,0 \mathrm{mg} / \mathrm{Kg}$, not dependent to animal size. An antagonist drugs were used some from alfa-2 antagonistic.

Keywords: Primates, Containment, Anesthetics. 
MIRANDA, C.B. et al. Contenção farmacológica em primatas não-humanos com emprego de ketamina e xilazina. Uma revisão bibliográfica. PUBVET, Londrina, V. 5, N. 8, Ed. 155, Art. $1045,2011$.

\section{INTRODUÇÃO}

O uso de agentes anestésicos na contenção farmacológica de animais silvestres constitui-se prática que possibilita realizar exames clínicos, pequenas cirurgias, tratamentos, coletas de material para exames laboratoriais, entre outros procedimentos que são de difícil realização sem que o animal esteja ou se encontre sedado. Entretanto na maioria dos casos, dependendo da circunstância, é necessário realizar contenção física do animal, que pode ser feita através de luva de couro, puçás, redes, manobras, gaiola de contenção, cevas (BECK e DRESNER, 1972).

Deve-se salientar que a contenção mecânica constitui ato extremamente estressante para o animal silvestre, e a intensidade e prolongamento deste estímulo pode produzir graves conseqüências (DINIZ, 1997).

A contenção química é o adjunto extremamente importante da prática de contenção física, regra particular em animais silvestres. Todavia, esta longe do universo ideal. Aquele que trabalha extensivamente com animais silvestres sabe que, não é um simples agente químico ou um grupo de agentes químicos que cumprirá com satisfação e eficácia os requerimentos de qualidade para aplicação universal. (FOWLER, 1995).

Com o animal devidamente contido pode-se proceder à contenção farmacológica deste, de acordo com a espécie e porte. Caso seja difícil ou impossível realizar a contenção mecânica do animal, utiliza-se equipamentos para injeção a distância como pistolas, espingardas, zarabatanas.

Problemas relatados na administração de agente químico em primatas não-humanos freqüentemente são de três tipos: 1) dosagem da droga; 2) controle da temperatura em animais muito pequenos. 3) administração em animais de grande porte. Eficácia e adequação deverão ser as duas considerações primárias na seleção da droga e sempre que possível, respeitar o jejum alimentar de 6 horas para primatas de grande porte (MARTIN, 1986). 
MIRANDA, C.B. et al. Contenção farmacológica em primatas não-humanos com emprego de ketamina e xilazina. Uma revisão bibliográfica. PUBVET, Londrina, V. 5, N. 8, Ed. 155, Art. 1045, 2011.

A estimativa do peso é importantíssima, para que não haja subdosagem ou ao contrario, pois poderá provocar até mesmo a morte do animal. As vias de administração podem ser, intramuscular, subcutânea ou intravenosa sendo que estas duas últimas só serão possíveis após a contenção física do animal (HALL e CLARCK, 2001).

Em vista da deficiência de trabalhos e experimentos na área, a proposição do presente estudo é realizar uma contribuição bibliográfica, sobre os efeitos clínicos e fisiológicos provocados pelo o emprego de ketamina e xilazina na contenção e anestesia de primatas não-humanos, já que este protocolo é bastante utilizado em zoológicos e também na captura de animais de vida livre.

\section{REVISÃO DE LITERATURA}

\subsection{Cloridrato de xilazina}

O Cloridrato de xilazina foi sintetizado pela primeira vez em 1962 e recebeu o nome de cloridrato de Bay Va 1470. Quimicamente é o cloridrato de 2(2,6 - dimetilfenilamino)-4H-5-6-diidro-1,3-tiazina. Farmacologicamente é classificada como um analgésico, assim como um sedativo e relaxante muscular esquelético. Não é um agente neuroléptico ou tranqüilizante, nem um agente anestésico (BOOTH, 1992).

O ponto de fusão desse fármaco dá-se aos 164 a 1670 C. Sua forma molecular é $\mathrm{C}_{12} \mathrm{H}_{6} \mathrm{~N}_{2} \mathrm{SHCl}$ e seu peso molecular é de 256,8 . É composto por cristais incolores de sabor amargo, solúveis em metanol e água, mas insolúveis em éter e clorofórmio. A solução a $2 \%$ contém $23,32 \mathrm{mg}$ da base (NOVAES, 1999). 
MIRANDA, C.B. et al. Contenção farmacológica em primatas não-humanos com emprego de ketamina e xilazina. Uma revisão bibliográfica. PUBVET, Londrina, V. 5, N. 8, Ed. 155, Art. 1045, 2011.

A xilazina enquadra-se no grupo dos miorrelaxantes. Nesta classe de fármacos incluem-se os medicamentos capazes de produzir relaxamento muscular por ação central (MASSONE, 2008).

Os alfa $_{2}$-agonistas como xilazina, detomidina e medetomidina são extensamente utilizados para a sedação, hipnose e imobilização de animais para uma variedade de procedimentos cirúrgicos. Para a reversão destes efeitos poderão ser utilizados os alfa2-antagonistas, como a iombina, tolazoline, idazoxan e atipamezole, que promovem uma alternativa fácil e segura para descontinuar sedação ou anestesia quando já não é requerida (AANTAA, 2000).

\subsubsection{Sistema Nervoso Central (SNC)}

Ações sedativas e analgésicas são relatadas ao deprimir o SNC, mediada por estimular os receptores alfa 2 -adrenérgicos (HSU, 1996).

A xilazina é um potente alfa 2 -agonista adrenérgico, age no SNC por ativação ou estimulação de adrenorreceptores alfa, tais como os adrenorreceptores alfa $_{2}$; isto aumenta a descarga simpática e reduz liberação de noradrenalina. Receptores que controlam o armazenamento e/ou a liberação de dopamina neuronal central e noradrenalina são adrenorreceptores alfa $_{2}$ (HEDLER et al., 1981).

Um misto de alfa $_{1} / a_{\text {alfa }}$ agonista, tem sido utilizada nos últimos anos como um sedativo analgésico em animais. No SNC os alfa ${ }_{2}$ agonistas induzem ambos analgesia e sedação, não diferente daquele produzido pela ação dos receptores opióides. Existem duas reações para os efeitos similares desses compostos. Primeiramente os receptores alfa 2 agonistas e opióides se estabeleceram na mesma região do cérebro e até mesmo sobre um mesmo neurônio. Esses receptores geralmente agem com o mesmo mecanismo de ação além do mesmo receptor. A união de qualquer um dos dois receptores 
MIRANDA, C.B. et al. Contenção farmacológica em primatas não-humanos com emprego de ketamina e xilazina. Uma revisão bibliográfica. PUBVET, Londrina, V. 5, N. 8, Ed. 155, Art. 1045, 2011.

alfa $_{2}$ adrenérgicos ou opióides a seus receptores resulta na ativação dos mesmos sinais transmitidos no sistema (isto é, associado à proteína $\mathrm{G}$ da membrana). Essas proteínas induzem uma corrente de eventos atuando nos canais de potássio da membrana pós-sináptica do neurônio, causa na célula perda de potássio, tornando-a cada vez mais negativamente carregada (hiperpolarizada) à medida que íons positivos movem-se para o espaço extracelular. Esta ação torna a célula insensível ao impulso excitatório. Conseqüentemente os alfa $_{2}$ agonistas e opióides podem produzir o mesmo evento farmacodinâmico por que: a) os receptores embora diferentes podem se estabelecer no mesmo lugar no cérebro ate no mesmo neurônio; b) esses tipos de receptores são duplos para o mesmo sinal transmitido; c) o mecanismo de transmissão do sinal está ligado ao mesmo mecanismo efetuado (isto é, os canais de potássio). Portanto, a ação efetuada no SNC é bastante similar entre esses sistemas receptores e seus agonista (LUMB e JONES, 1996).

A xilazina causa progressiva depressão do SNC, levando inicialmente à sedação, possuindo uma larga margem de segurança. Aumentando a dose em geral não aumenta o grau de sedação, mas prolonga a duração do efeito (KLIDE, 1985). Sob doses mais elevadas, a hipnose e a inconsciência tornamse mais prolongada, sendo acompanhadas de analgesia relacionada à dose, e relaxamento muscular, centralmente mediado. (HALL e CLARCK,2001).

Acredita-se que o locus cereleus seja o maior sitio de ação para a

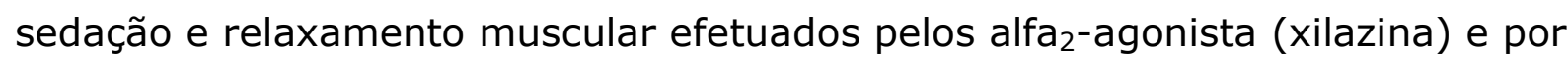
apresentar esta propriedade são bem utilizados em Medicina Veterinária (LUMB e JONES, 1996). 
MIRANDA, C.B. et al. Contenção farmacológica em primatas não-humanos com emprego de ketamina e xilazina. Uma revisão bibliográfica. PUBVET, Londrina, V. 5, N. 8, Ed. 155, Art. 1045, 2011.

\subsubsection{Sistema Cardiovascular}

Em geral a xilazina causa uma depressão dose dependente no sistema cardiovascular que é, contudo, modificada por complexos efeitos sobre o sistema nervoso autônomo. Ela produz estimulação ou inibição dos sistemas simpático e parassimpático. O resultado final depende da dose, via de administração e espécie de animal em questão. A xilazina pode determinar intensa vasoconstrição, além de um efeito alfa-simpatomimético (SCHMIDT et al., 1970), eleva o tônus vagal e a atividade dos barorreceptores através de uma ação central (ANTONACCIO et al., 1987).

Ocorre queda transitória e moderada da pressão arterial, precedida de elevação de curta duração com diminuição da freqüência cardíaca, o que a torna desaconselhável em pacientes de alto risco (MASSONE, 2008).

Quando administrada pela via intravenosa em injeção contínua, induz bradicardia e um curto período de hipertensão (5 a 10 minutos), seguido por uma não mais duradoura diminuição no débito cardíaco e pressão sanguínea (KRONEBERG, 1996).

Não é incomum decréscimo no débito cardíaco de $1 / 3$ (um terço) para $1 / 2$ (um meio) e decréscimo na pressão sanguínea de 1/4 (um quarto) para 1/3 (um terço). Esses efeitos são observados em quase todas as espécies. A hipertensão inicial causada é devido à ação periférica de receptores adrenérgicos, produzindo tranqüilizarão, contração da musculatura lisa e vasoconstrição. Eventual redução na pressão sanguínea é devido ao decréscimo do tônus simpático sob a ação da xilazina nos nervos central e pré-

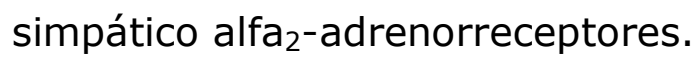

Os efeitos arritmogênicos da xilazina mais comumente encontrados incluem-se bloqueio sinoatrial, atrioventricular, bradicardia, bloqueio cardíaco de $1^{\circ}$ e $2^{\circ}$ graus, dissociação atrioventricular e arritmia sinusal (DUNKLE, 1986; GREEN, 1988). 
MIRANDA, C.B. et al. Contenção farmacológica em primatas não-humanos com emprego de ketamina e xilazina. Uma revisão bibliográfica. PUBVET, Londrina, V. 5, N. 8, Ed. 155, Art. 1045, 2011.

\subsubsection{Sistema Respiratório}

A xilazina produz uma depressão dose dependente relacionada dos centros respiratórios, resultando na redução da freqüência e do volume corrente (HALL e CLARCK, 2001; MASSONE, 2008).

\subsubsection{Outros Efeitos}

Na musculatura esquelética causa relaxamento por ação central, o que permite boas manipulações. Quanto à musculatura lisa reduz o tônus intestinal (intestino grosso), evitando a emissão de fezes. À temperatura corpórea ocorre inicialmente elevação de até $1^{\circ} \mathrm{C}$, tendendo a normalidade decorrida aproximadamente 3 horas da aplicação de xilazina (MASSONE, 2008).

Alterações na função gastrointestinal após administração deste farmaco foram relatadas em diversas espécies. Uma delas é o vômito, que tem estado vinculado à ativação do centro alfa 2 -adrenorreceptor (HIKASA, 1996).

Promove contrações uterinas, não devendo ser aplicada nos estágios finais da gestação, pois pode induzir o trabalho de parto prematuro. Parece desaconselhável usar a xilazina em qualquer animal que esteja sofrendo de obstrução no trato respiratório superior, pois as propriedades miorrelaxnates da droga parecem acentuar os efeitos da obstrução (HALL e CLARCK, 2001).

\subsection{CLORIDRATO DE KETAMINA}

\subsubsection{Anestesia Dissociativa}

O termo anestesia dissociativa é usado para descrever um estado de anestesia induzido por drogas que interrompem a transmissão, ascendendo 
MIRANDA, C.B. et al. Contenção farmacológica em primatas não-humanos com emprego de ketamina e xilazina. Uma revisão bibliográfica. PUBVET, Londrina, V. 5, N. 8, Ed. 155, Art. 1045, 2011.

estado de inconsciência do cérebro, ao invés de depressão generalizada de todos os centros do cérebro (CORSSEN, 1996). ' 'É capaz de dissociar o córtex cerebral de maneira seletiva, causando analgesia e "desligamento", sem perda, porém, dos reflexos protetores (MASSONE, 2008).

Caracteriza-se por um estado cataléptico em que os olhos permanecem abertos com um lento nistágmo, olhar fixo, variando graus de hipertonicidade e reflexos músculos esqueléticos ocorrem não relacionados à estimulação cirúrgica. Defini-se como um "estado acinético característico, com a perda dos reflexos ortostáticos, mas sem prejuízo da consciência, em que as extremidades parecem estar paralisadas por falência motora e sensorial" (LUMB e JONES, 1996; CONDY et al., 2005).

$\mathrm{Na}$ eletroencefalografia (EEC), há evidencia de dissociação entre o tálamo e o sistema límbico (LUMB e JONES, 1996).

Os animais permanecem com olhos abertos, apresentando bom tônus nos músculos mandibulares, com reflexos laringeais e faringeais ativos, enquanto que a analgesia aparenta ser extremamente boa (HALL e CLARCK, 2001; BUNCH et al., 2008).

Ketamina é o cloridrato de di-2-(o-clorofenil)-2-(metilamino) ciclohexanona. Comercializado em concentrações de $10 \mathrm{mg} / \mathrm{ml} ; 50 \mathrm{mg} / \mathrm{ml} \mathrm{e}$ $100 \mathrm{mg} / \mathrm{ml}$, sendo apropriada para injeção intramuscular, intravenosa e oral. A solução de $10 \mathrm{mg} / \mathrm{ml}$ é tornada isotônica com o cloreto de sódio (HALL e CLARCK, 2001; PULLEY; ROBERTS; LERCHE, 2004; SPRINGER e BAKER, 2007; WINTERBORN e. al., 2008).

Posssui peso molecular de 237,44; ponto de fusão de 262 a $263^{\circ} \mathrm{C}$, sua fórmula molecular é $\mathrm{C}_{13} \mathrm{H}_{17} \mathrm{Cl}_{12} \mathrm{NO}$; apresenta-se como um pó cristalino, formando solução límpida e estável no meio ambiente. Seu componente básico é composto por $86,7 \%$ de seu sal; o pH é 3,5 a 5,5 e sua preparação de $50 \mathrm{mg} / \mathrm{ml}$ (solução a $5 \%$ ) ou $100 \mathrm{mg} / \mathrm{ml}(10 \%)$. Seu preservativo é o femorol $\mathrm{R}$ 
MIRANDA, C.B. et al. Contenção farmacológica em primatas não-humanos com emprego de ketamina e xilazina. Uma revisão bibliográfica. PUBVET, Londrina, V. 5, N. 8, Ed. 155, Art. $1045,2011$.

(cloreto de benzetônio), a 1:10000, tem meia vida de seis minutos (MASSONE, 2008).

\subsubsection{Sistema Nervoso Central (SNC)}

Ainda não se identificou um receptor celular específico no cérebro para a ketamina, entretanto há forte evidencia da existência de um receptor da fenciclidina (PERT e QUIRION, 1992).

Os efeitos sobre o SNC são similares aos da fenciclidina, agindo por estimulação ou depressão; o efeito varia consideravelmente, dependendo da espécie considerada, e da dose aplicada (HALL e CLARCK, 2001).

Como é congênere da fenciclidina, é lógico pensar que esta deva possuir alta afinidade pelo receptor da fenciclidina. Entretanto pode não ser o caso porque o mecanismo para analgesia pela ketamina pode ser mediado por receptores opióides (BOOTH, 1992).

Intensa analgesia ocorre na dose subanalgésica com elevado limiar de dor correlacionada com o nível plasmático de $0,1 \mathrm{ug} / \mathrm{ml}$ ou maior. 0 mecanismo proposto responsável pela ação analgésica, inclui bloqueio do trato espinocelular, depressão do núcleo da formação medular do retículo da lamina, interação com o SNC, receptores medulares opiáceos e receptores antagonistas N-metil-D-aspartato (NMDA) (LUMB e JONES, 1996).

Os aminoácidos excitatórios como glutamato e aspartato, agindo predominantemente com receptores N-metil-D-aspartato (NMDA), estão envolvidos na regulação central da secreção de vários hormônios pituitários anteriores inclusive prolactina (PRL), considerando que a ketamina, um anestésico extensamente usado, foi indicado para antagonizar uma variedade de receptores NMDA mediados por estes aminoácidos excitatórios (RIZVI et al., 2000). 
MIRANDA, C.B. et al. Contenção farmacológica em primatas não-humanos com emprego de ketamina e xilazina. Uma revisão bibliográfica. PUBVET, Londrina, V. 5, N. 8, Ed. 155, Art. 1045, 2011.

Comportamento alucinógeno podendo progredir para delírio, ocorre durante a emergência da anestesia com ketamina. Esta produz depressão dos núcleos colliculus inferior e geniculado medial, resultando em perda da percepção, de audição e visão, que se estimulados podem ser responsivos para essas reações (LUMB e JONES, 1996).

Induz anestesia e amnésia por ruptura funcional (dissociação) do SNC, mediante estímulo acentuado do SNC ou indução de um estado cataleptóide (BOOTH, 1992).

Essas reações normalmente desaparecem dentro de várias horas sem recorrência. Pré-medicação ou administração concorrente de xilazina, acetilpromazina ou um derivado benzodiazepínico (midazolan ou diazepan) diminuem a incidência da emergência dessas reações (TOFT, 1996).

\subsubsection{Sistema Cardiovascular}

A ação da ketamina nesse sistema é caracterizada por estimulação indireta cardiovascular. Vários efeitos sobre organismos alvo incluem: 1) efeito simpatomimético mediado pelo SNC; 2 ) vasodilatação direta do músculo liso do endotélio vascular; 3) efeito inotrópico no miocárdio (LUMB e JONES, 1996).

Por apresentar ação simpatomimética, a ketamina estimula a freqüência cardíaca, exerce ação vasoconstritora periférica, elevando dessa maneira, consideravelmente a pressão arterial. Por isso a ketamina é indicada em casos de choque, especialmente os hemorrágicos sendo, porém, contra-indicada em animais idosos e hipertensos. A elevação da freqüência cardíaca pode ser atribuída ao aumento do debito cardíaco (MASSONE, 2008).

A ketamina também aumenta a pressão aórtica média, pressão arterial pulmonar, e a pressão venosa central. Há indícios de que o sistema 
MIRANDA, C.B. et al. Contenção farmacológica em primatas não-humanos com emprego de ketamina e xilazina. Uma revisão bibliográfica. PUBVET, Londrina, V. 5, N. 8, Ed. 155, Art. 1045, 2011.

adrenérgico deve estar intacto para que ocorram essas respostas cardiovasculares. Conseqüentemente é provável que aja diretamente, por inibição da captação neuronal de catecolaminas, especialmente a noradrenalina. Essas propriedades estimulantes cardíacas, além de sua ação antiarrítmica, fazem da ketamina um bom agente indutor para pacientes de pouco risco e hipovolêmicos (BOOTH, 1992; HOTCHKISS, 2007).

Induz significativo aumento da pressão sanguínea intracerebral, pressão intracraniana e pressão do fluido cérebro espinhal como resultado da vasodilatação do cérebro e elevação do sistema de pressão sanguínea (LUMB e JONES, 1996).

\subsubsection{Sistema Respiratório}

A ketamina não altera significativamente a freqüência respiratória, mantendo livres as vias aéreas, com presença de reflexos protetores (MASSONE, 2008).

Difere mais dos outros anestésicos visto que sua ação não deprime ventilação em resposta a hipóxia. O tônus músculo esquelético é mantido ou até mesmo aumentado, portanto oxigenação arterial e capacidade funcional residual são usualmente bem mantidas durante essa anestesia. Monitoramento das vias aéreas e/ou intubação endotraqueal poderá sempre ser realizada evitando aspiração (LUMB e JONES, 1996).

Uma leve depressão respiratória foi relatada e, na clínica, isto normalmente se manifesta por uma velocidade aumentada, que não é compensada por um volume corrente reduzido. Embora os reflexos laringeais possam estar presentes ainda é necessária para as vias aéreas uma atenta observação, pois o grau de proteção das vias aéreas superiores é menor do que se supunha anteriormente. Causa sialorréia e aumento da secreção 
MIRANDA, C.B. et al. Contenção farmacológica em primatas não-humanos com emprego de ketamina e xilazina. Uma revisão bibliográfica. PUBVET, Londrina, V. 5, N. 8, Ed. 155, Art. 1045, 2011.

mucosa do trato respiratório superior que pode ser facilmente controlada por administração de um anticolinérgico. Apesar disso, o reflexo de deglutição pode ser mantido, porque a maioria das espécies podem ser intubadas quando anestesiadas com ketamina (HALL e CLARCK, 2001).

\subsubsection{Função Neuromuscular}

A ketamina é bem utilizada com sucesso na maioria das espécies, e as doses variam largamente de uma espécie para outra. O tempo de indução e duração da imobilização são dependentes da dose e da espécie. Em doses ótimas, os primeiros efeitos são observados de 2 a 5 minutos após a administração intramuscular, com plenos efeitos alcançados de 5 a 10 minutos, O tempo de duração da imobilização é de 45 a 120 minutos, mas em alguns animais podem ser consideravelmente longas (LUMB e JONES, 1996).

A ketamina produz pouco (ou nenhum) relaxamento muscular (HALL e CLARCK, 2001). Ocorre aumento do tônus muscular (hipertonia), com ligeiras contrações (estado cataleptóide) (MASSONE, 2008).

\subsubsection{Efeitos Metabólicos}

A ketamina é metabolizada pelo fígado e eliminada pelos rins. Em macacos foram recuperadas na urina 94 a $97 \%$ dos metabolitos (MASSONE, 2008).

A biotransformação ocorre no fígado por N-desmetilação e hidroxilaçao do anel cicloexanona, com transformação de derivados hidrossolúveis do glucoronídio, que são eliminados na urina (WHITE e TREVOR, 1982; PERUMAL et al., 2007). 
MIRANDA, C.B. et al. Contenção farmacológica em primatas não-humanos com emprego de ketamina e xilazina. Uma revisão bibliográfica. PUBVET, Londrina, V. 5, N. 8, Ed. 155, Art. $1045,2011$.

A rápida recuperação após a administração de ketamina é causada por rápida redistribuição do SNC, para todos os tecidos do corpo, principalmente tecidos gordurosos, pulmões, fígado e rins (LANNING, 1975).

Não há evidência de desenvolvimento de tolerância, depois de repetidas injeções de ketamina, não foram descritos efeitos cumulativos significativos. Injeções diárias de ketamina em ratos, cães e macacos não causaram alterações nos valores hematológicos, na urina ou medula óssea, ou na química do sangue (HALL e CLARCK, 2001).

A ketamina poderá ser usada cautelosamente em animais com disfunção hepática ou renal. Clinicamente, animais com disfunção hepática não metaboliza ketamina tão rapidamente quanto animais normais. Animais com disfunção renal ou obstrução do fluxo urinário igualmente tem sonolência prolongada (LUMB e JONES, 1996; VENKATESAN, 2006).

A anestesia pela ketamina não parece alterar as funções endócrina no macaco comedor de caranguejo (Macaca fascicularis) ou macaco rhesus (Macaca mulatta) (FULLER et al., 1984).

Os efeitos farmacológicos da ketamina podem ser antagonizados quase imediatamente pela administração de ioimbina (BOOTH, 1992).

\subsection{ASSOCIAÇÃO KETAMINA E XILAZINA NA CONTENÇÃO DE PRIMATAS NÃO-HUMANOS}

A ketamina foi primeiramente introduzida na clínica veterinária na Inglaterra, difundindo-se então para todo o mundo. $O$ primeiro trabalho empregando-a para imobilizar animais silvestres foi reportado por Dolensek, em 1971, utilizando a droga em leopardos-da-neve. No Brasil, a utilização da ketamina foi reportada inicialmente por Diniz, em 1974, quando foi apresentada relação de 165 mamíferos e 34 aves, notadamente os da fauna brasileira, que foram imobilizados para sofrerem intervenção de curta duração, 
MIRANDA, C.B. et al. Contenção farmacológica em primatas não-humanos com emprego de ketamina e xilazina. Uma revisão bibliográfica. PUBVET, Londrina, V. 5, N. 8, Ed. 155, Art. 1045, 2011.

durante o período de 1971 a 1974. Fato interessante é que o emprego da ketamina no Brasil teve início com animais silvestres antes mesmo da utilização em animais domésticos (DINIZ, 2006).

A ketamina por ser um anestésico dissociativo de ação rápida, deve ser aplicada lentamente por via intravenosa, a fim de se evitar alteração dos parâmetros fisiológicos de maneira abrupta, fato não observado quando aplicado por via intramuscular. Por via intravenosa lenta, as doses recomendadas são de $2-6 \mathrm{mg} / \mathrm{kg}$, dependendo da qualidade anestésica desejada. O período de latência por via intramuscular é de 5 a 10 minutos, com período anestésico hábil de 30 a 45 minutos e período de incubação idêntico (MASSONE, 2008).

A ketamina não atinge o estágio III de anestesia, promove efeitos catalépticos, analgésico e anestésico em animais silvestres. Em primatas e felinos observa-se em geral sialorréia, pálpebra abertas e reflexo laringofaringeano ativos. Estes movimentos podem ser interpretados, inadvertidamente, como decorrentes de subdoses, induzindo o veterinário inexperiente a administrar doses adicionais (DINIZ, 1997).

Durante as últimas três décadas, médicos veterinários usaram vários

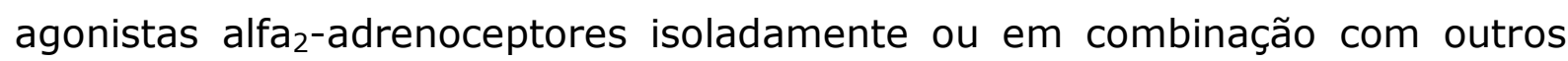
analgésicos e anestésicos alcançando sedação, analgesia centralmente mediada, para imobilização de animais (TRANQUILLI e MAZE, 2000).

Até recentemente, o agonista alfa 2 -adrenoceptor mais comumente empregado era xilazina. Isto foi em particular usado em combinação com ketamina para sedação e anestesia, em um sortimento grande de espécies, como cães, gatos, ovelhas, gado, cavalos, animais de laboratório e muitas espécies de mamíferos exóticos (GREEN e THURMON, 2000).

Primatas são facilmente manipulados com agentes químicos. Felizmente os níveis e dosagem de cada droga são essencialmente os mesmo em toda parte. Ketamina é usada em $8-15 \mathrm{mg} / \mathrm{kg}$ e depende da duração do 
MIRANDA, C.B. et al. Contenção farmacológica em primatas não-humanos com emprego de ketamina e xilazina. Uma revisão bibliográfica. PUBVET, Londrina, V. 5, N. 8, Ed. 155, Art. 1045, 2011.

procedimento ou tamanho da espécie (indivíduos menores requerem doses mais altas) (FOWLER, 1995).

A ketamina tem permissão da United States Food and Drug Administation (FDA) para ser usado no homem, gato doméstico e primatas não-humanos. Entretanto, também tem segurança e eficácia quando usada para anestesia em numerosas outras espécies de animais silvestres, répteis e pássaros, mas não é apropriada para ungulados. Pode ser administrada oralmente e parenteralmente. Em espécies silvestres, a administração, intramuscular ou subcutânea são aceitáveis. A variação na dose para imobilização é enorme $(2-50 \mathrm{mg} / \mathrm{kg})$.

A administração isolada promove efeito satisfatório em primatas e felinos, salientando-se que os animais de pequeno porte necessitam de doses mais elevadas que as espécies de médio e grande porte. A dose recomendada de ketamina para pequenos primatas com peso de $0,1-1,0 \mathrm{~kg}$ é de $15-20$ $\mathrm{mg} / \mathrm{kg}$, para primatas de médio porte de $2-20 \mathrm{~kg}$ de peso, $10-15 \mathrm{mg} / \mathrm{kg}$ e para primatas de grande porte de $25-200 \mathrm{~kg}$ de peso é de $5-10 \mathrm{mg} / \mathrm{kg}$. Xilazina é recomendada na dose de $0,5-2,0 \mathrm{mg} / \mathrm{kg}$. São considerados primatas de pequeno porte os calitricídeos como o sagüi (Callithrix jacchus), o mico leão (Leontophitecus $s p$ ) e outros; de médio porte os cebídeos nacionais como o macaco prego (Cebus apella), o macaco aranha (Ateles $s p$ ) e outros, bem como os exemplares da fauna africana como o rhesus (Macaca mulatta) e babuíno (Papio cynocephalus); e os primatas de grande porte como o chimpanzé (Pan toglodytes) e o gorila (Gorilla gorilla) (DINIZ, 1997; YOSHIZAWA et al., 2005; SLIKKER et. al., 2007).

Em primatas, gatos e porcos a ketamina produz profunda analgesia sem relaxamento muscular, espasmos tônico-clônicos dos músculos dos membros poderão ocorrer, mesmo na ausência de estimulação cirúrgica ou de outro tipo qualquer. A salivação é aumentada, oque que pode obstruir as vias aéreas, 
MIRANDA, C.B. et al. Contenção farmacológica em primatas não-humanos com emprego de ketamina e xilazina. Uma revisão bibliográfica. PUBVET, Londrina, V. 5, N. 8, Ed. 155, Art. 1045, 2011.

mesmo se mantendo os reflexos laringeais e faringeais (HALL e CLARCK, 2001).

Desde o início de sua aplicação, a ketamina atingiu número extremamente elevado de aplicação em primatas, salientando-se raros casos de acidente em decorrência da droga. Entretanto, conforme foi constatado em macaco pode ocorrer depressão respiratória irreversível, culminando em morte, caso o animal apresente quadro pneumônico (DINIZ, 1997).

A ketamina deve ser evitada em macacos-esquilo (Callithrix $s p$ ) e sagüis (Callithrix jacchus), para contenção química ou anestésica (HALL e CLARCK, 2001).

Tem-se dado preferência à associação de ketamina e xilazina devido à abolição do efeito depressor profundo provocado pela xilazina, bem como a abolição da catatonia que a ketamina produz, sendo importante frisar que o efeito sedativo e anestésico é alcançado quando estes medicamentos são aplicados em associação, ao passo que, se administrados isoladamente, o efeito é de menor intensidade (DINIZ, 1997).

O uso de dissociativos para a contenção como pré-anestesia revolucionou a manipulação de primatas. Usando a contenção em gaiolas que permitem injeção intramuscular, um único indivíduo pode imobilizar muitos animais em pouco tempo. Como diretriz ketamina na dose de $10-15 \mathrm{mg} / \mathrm{kg}$ intramuscular, na maioria dos casos resulta em primatas imobilizados, o que é adequado para executar exames, passagem de sonda uretral, cateterização cardíaca, coleta de sangue, tratamento de feridas e prova de tuberculose. A dose de $15-30 \mathrm{mg} / \mathrm{kg}$ intramuscular normalmente projeta anestesia cirúrgica. Dose maior (20-30 $\mathrm{mg} / \mathrm{kg}$ ) de ketamina é normalmente necessário para que se produza anestesia cirúrgica em primatas menores e prossímios, porem dose menores (6-10 $\mathrm{mg} / \mathrm{kg}$ ) são suficientes para grandes macacos. Não foram relatadas tolerância para ketamina repetindo administração em primatas (KUHN, 1996). 
MIRANDA, C.B. et al. Contenção farmacológica em primatas não-humanos com emprego de ketamina e xilazina. Uma revisão bibliográfica. PUBVET, Londrina, V. 5, N. 8, Ed. 155, Art. 1045, 2011.

Tem sido estudado o efeito anestésico da associação de ketamina e xilazina na dose proporcional em macacos rhesus (Macaca mulatta). Ketamina intramuscular somente a uma dose de $2,5 \mathrm{mg} / \mathrm{kg}$ não produz anestesia. Xilazina sozinha a menos de $2 \mathrm{mg} / \mathrm{kg}$ intramuscular induz sedação, considerando que a adição de xilazina à ketamina produz anestesia, cuja duração é uma função logarítmica da dose de xilazina. Os efeitos da dose intramuscular de ketamina na função cardiovascular em babuíno (Papio cynocephalus) têm sido avaliados. O débito cardíaco, pico de velocidade e aceleração de fluxo aórtico estão deprimidos, índice de batimentos cardíacos e volume estão ligeiramente diminuídos (LUMB e JONES, 1996).

Administração de ketamina a $15-20 \mathrm{mg} / \mathrm{kg}$ intramuscular mantém níveis efetivos de anestesia para venopunção em chimpanzés (Pan toglodytes) de 1236 meses. Para procedimentos como biópsias com agulha percutânea que requerem tempos de anestésico mais longo a xilazina (1 $\mathrm{mg} / \mathrm{kg})$ foi administrada com a ketamina. Mais de 1600 procedimentos foram executados com esse protocolo anestésico em 23 chimpanzés por um período de 18 meses sem mortalidade. A recuperação era tranqüila e sem transtornos (APRIL et al., 1981).

A adição de xilazina para ketamina levou ao aumento da analgesia, anestesia, e relaxamento muscular em macacos rhesus (Macaca mulatta). Esta combinação promove anestesia adequada para procedimentos tais como punção cisternal, punção espinhal lombar, inserção de cateteres urinários, amputações de dedo, e tatuagem. A combinação de ketamina e xilazina deprimiu a freqüência cardíaca, freqüência respiratória, e temperatura de corpo mais que a administração de ketamina isoladamente. O período de anestesia também era prolongado, mas os macacos recuperaram consciência mais rapidamente ao término do período anestésico (BANKNIEDER et al., 1978). 
MIRANDA, C.B. et al. Contenção farmacológica em primatas não-humanos com emprego de ketamina e xilazina. Uma revisão bibliográfica. PUBVET, Londrina, V. 5, N. 8, Ed. 155, Art. 1045, 2011.

As diminuições na contagem de eritrócitos, concentração de hemoglobina, contagem total de leucócitos e linfócitos após injeção de ketamina observada em macaco rhesus (Macaca mulatta) provavelmente pode ser atribuído a uma reversão de tensão ou reação de alarme (BENNET et al., 1992).

Em trabalho com macaco rhesus (Macaca mulatta) também se observou diminuição em eritrócitos periféricos e linfócitos como resultado de redistribuição destas células do sangue circulante para mo baço (LOOMIS et al., 1980).

Injeção intramuscular de ketamina e xilazina em macaco rhesus (Macaca mulatta) proveu boa indução anestésica, uma larga margem de segurança e nenhum efeito colateral significante. O tempo de indução e recuperação, a duração de anestesia, e a habilidade de termorregulação podem ser afetados por combinações diferentes de ketamina e xilazina. A adição d xilazina para ketamina aumenta relaxamento de músculo, tempo de recuperação e duração de anestesia, enquanto geralmente decresce o tempo de indução e habilidade de termorregulação (NACCARATO e HUNTER, 1979).

Macacos rhesus (Macaca mulatta) foram anestesiados por via intramuscular com ketamina ( $7 \mathrm{mg} / \mathrm{kg}$ ) e xilazina $(6 \mathrm{mg} / \mathrm{kg})$, tiopental sódico $(2,5 \%)$ foi aplicado por via intravenosa para intubação e anestesia foi mantida com isoflurano $(0,5$ a 1,5\%) e oxigênio, durante a colocação cirúrgica de cateter temporário na região subaracnóidea cerebral para realizar prova de fluido cérebro espinhal (BACHER et al., 1991).

O babuíno (Papio ursinus) é extensivamente usado na África do Sul para pesquisa biomédica. Sendo um primata de grande porte, sempre é necessário aplicar alguma medida de substancia química ou restrição física e a combinação de ketamina e xilazina tem sido bastante utilizada. Foi achado que ketamina e xilazina eram agentes de restrição química satisfatórios que 
MIRANDA, C.B. et al. Contenção farmacológica em primatas não-humanos com emprego de ketamina e xilazina. Uma revisão bibliográfica. PUBVET, Londrina, V. 5, N. 8, Ed. 155, Art. $1045,2011$.

produziram um estado fisiológico estável por mais de 90 minutos (GOOSEN et al., 1987).

Colecionou-se amostras de sangue de 124 macacos pregos (Cebus apella) da Fundação Parque de Zoológico de São Paulo, anestesiados com ketamina (10 mg/kg intramuscular), constatando-se que machos adultos apresentam valores hematológicos mais altos que outros grupos especialmente as fêmeas adultas e fêmeas jovens. Esta observação pode ser determinada pela massa muscular maior do grupo de machos (LARSSON et al., 1999).

No babuíno (Papio cynocephalus), uma combinação de ketamina (11 $\mathrm{mg} / \mathrm{kg})$ e xilazina $(0,5 \mathrm{mg} / \mathrm{kg})$, administrada por via intramuscular em injeção única, aumenta o tempo de sono, diminuindo a freqüência cardíaca, confere bom relaxamento muscular, previne o movimento muscular voluntário e permite passagem de tubo endotraqueal (WHITE e CUMMINGS, 1979).

$\mathrm{Na}$ eventualidade de ser utilizada a combinação deve-se ter cuidado porque as funções vitais ficam comprometidas (BOOTH, 1992).

O trabalho com macaco rhesus (Macaca mulatta) indica que a combinação de ketamina e xilazina leva à diminuição na ventilação alveolar, subseqüente modificações nas tensões de gases sanguíneos que provavelmente se devem ai conteúdo de ketamina na combinação. Os efeitos benéficos da combinação verificados clinicamente são prejudicados em termos fisiológicos. A presença de pequena quantidade de xilazina nessa combinação domina o controle do sistema cardiovascular e anula o efeito benéfico da ketamina. Por outro lado, o componente ketamina da combinação domina os mecanismos de controle do sistema pulmonar e elimina em menor grau os efeitos benéficos da xilazina. O resultado final da combinação resulta em efeitos desfavoráveis sobre o sistema cardiopulmonar (REUTLINGER et al., 1980). 
MIRANDA, C.B. et al. Contenção farmacológica em primatas não-humanos com emprego de ketamina e xilazina. Uma revisão bibliográfica. PUBVET, Londrina, V. 5, N. 8, Ed. 155, Art. $1045,2011$.

\section{CONSIDERAÇÕES FINAIS}

A associação de ketamina e xilazina produz contenção farmacológica adequada e rápida recuperação, indicando-se a ketamina nas doses de 5-10 $\mathrm{mg} / \mathrm{kg}$ para primatas de grande porte, $10-15 \mathrm{mg} / \mathrm{kg}$ para primatas de médio porte e $15-20 \mathrm{mg} / \mathrm{kg}$ para primatas de pequeno porte e dose de xilazina de 0,5-2,0 $\mathrm{mg} / \mathrm{kg}$, embora exista diferença na resposta individual fisiológica de cada animal. As doses recomendadas variam de acordo com o porte de cada primata, por isso pela diferença de tamanho que cada grupo de primatas apresenta, não se pode estabelecer um protocolo único de dose dentro desta classe. Um dos efeitos indesejáveis provocados pela ketamina é a sialorréia que pode ser revertida com o uso de atropina que é um anticolinérgico. Os efeitos farmacológicos da ketamina e xilazina podem ser encurtados com o uso de ioimbina, que é um agente bloqueador alfa $_{2}$-antagonista especifico sobre os receptores pré-sinápticos.

Por outro lado o efeito sedativo e anestésico produzido por essa associação permite manusear primatas com boa margem de segurança para realizar procedimentos de curta duração e até mesmo pequenas cirurgias sem transmitir perigo de possíveis acidentes, caso seja administrada dosagem adequada.

Quando se procede a contenção farmacológica em primatas utilizando o protocolo de ketamina e xilazina no intuito de realizar exame clínico, pequenas cirurgias, coleta de matérias (sangue, urina, secreções), para exames complementares, seja qual for o procedimento a ser realizado, devem-se a todo tempo avaliar os parâmetros do animal (freqüência cardíaca, respiratória, pulso capilar, temperatura), monitorização da anestesia (visual, tátil, mecânica) a fim de que o veterinário possa avaliar a profundidade da sedação. 
MIRANDA, C.B. et al. Contenção farmacológica em primatas não-humanos com emprego de ketamina e xilazina. Uma revisão bibliográfica. PUBVET, Londrina, V. 5, N. 8, Ed. 155, Art. $1045,2011$.

\section{REFERÊNCIAS}

Aantaa R. Alpha2-adrenoceptor Antagonists. Baillie Are's Clinical Anaesthesiology 2000; 14(2):285-92.

Antonnaccio LE, Westfall BA, Short CR, In HALL, LW; CLARCK, KW. Anestesia Veterinária 8th. ed. São Paulo: Manole, 1987 p. 65.

April M, Tabor E, Getery RJ. Combination of ketamine and xylazine for effective anaesthesia of juvenile chimpanzees (Pan troglodytes). Lab Anim 1982; 16(2):116-8.

Bacher JD, Balis FM, McCully CL, Godwin KS. Cerebral subarachnoid sampling of cerebrospinal fluid in the rhesus monkey. Lab Anim Sci 1994; 44(2):148-52.

Banknieder AR, Phillips JM, Jackson KT, Vinal SI. Comparison of ketamina with the combination of ketamina and xylazine for effective anesthesia in the rhesus monkey (Macaca mulatta). Lab Anim Sci. 1978; 28(6):742-5.

Bennet JS, Gosset KA, McCarthy MP, Simpson ED. Efeitos do Cloridrato de ketamina em soro bioquímico e variáveis hematológicas em macacos rheso (Macaca mulatta). Vet Clin Pathol 1992; 21(1):15-18.

Booth NH, Macdonald LE. Farmacologia e Terapêutica Veterinária, 6th ed. Rio de Janeiro: Guanabara Koogan; 1992.

Bunch TJ, Tian B, Seeman JL, Gabelt BT, Lin TL, Kaufman PL. Effects of daily prolonged ketamine anesthesia on intraocular pressure in monkeys. Curr Eye Res 2008; 33(11):946-53.

Condy C, Wattiez N, Rivaud-Péchoux S, Gaymard B. Ketamine-induced distractibility: An oculomotor study in monkeys. Biol Psychiatry 2005; 57(4):366-72.

Corssen G, Miyasaka M, Domino EF. In: Lumb WV.; Jones EW. Veterinary Anesthesia, 3rd ed. Copyring Willians \& Wilkins; 1996. p. 241.

Diniz LSM. Imobilização química em animais silvestres. In: Spinosa HS, Górniak SL, Bernadi MM. Farmacologia aplicada à Medicina Veterinária. 4th ed. Rio de Janeiro: Guanabara Koogan; 2006 p. 198-200..

Diniz LSM. Primatas em cativeiro: manejo e problemas veterinários, enfoque nas espécies neotropicais. 1. ed. São Paulo: Ícone; 1997.

Dunkle, N, Moise NS. In: Lumb WV.; Jones EW. Veterinary Anesthesia, 3rd ed. Copyring Willians \& Wilkins; 1996. p. 197

Fowler ME. Zoo \& Wild Animal Medicine. 4th ed. Philadelphia: W.B. Saunders; 1993.

Fowler ME, editor. Restrain and Hadling of Wild and Domestic Animals. 2nd ed. Ames: Iowa State University Press; 1995.

Fuller GB, Hobson WC, Reyes FI. Proc Soc Exp Biol Med 1984; 175:487. 
MIRANDA, C.B. et al. Contenção farmacológica em primatas não-humanos com emprego de ketamina e xilazina. Uma revisão bibliográfica. PUBVET, Londrina, V. 5, N. 8, Ed. 155, Art. $1045,2011$.

Green SA, Thurmon JC. In: Aantaa R. Alpha2-adrenoceptor Antagonists. Baillie Are's Clinical Anaesthesiology 2000; 14(2):285-92.

Green CJ. Animal anaesthesia. In: Lumb, MV.; Jones, EW. Veterinary Anaesthesia. 3rd ed. Copyring Wiliams \& Wikins; 1996. p.197.

Goosen DJ, Davies JH, Maree M, Dormehl IC. The influence of hysical and chemical restraint on the physiology of the chacma baboon (Papio ursinus). Curr Eye Res 1987

Hall LW, Clarke KW, Trim CM. Veterinary Anaesthesia. 10th ed. Philadelphia: W. B. Saunders; 2001.

Hedler L, Stamm G, Weitzell R. Eur J Pharmacol 1981; 70:43.

Hikasa Y, Ogasawara S, Taskase K. In: Lumb WV.; Jones EW. Veterinary Anesthesia, 3rd ed. Copyring Willians \& Wilkins; 1996. p. 197.

Hotchkiss CE, Wang C, Slikker W Jr. Effects of prolonged exposure on cardiovascular physiology in pregnant and infant rhesus monkeys (Macaca mulatta). J Am Assoc Lab Anim Sci 2007; 46(6):21-8.

Hsu WH. In: Lumb WV.; Jones EW. Veterinary Anesthesia, 3rd ed. Copyring Willians \& Wilkins; 1996. p. 194.

Klide AM. Guide To The Care and Use of Experimental Animals - Canadia Consil on Animal Care.1985; 1:42-8.

Kroneberg G, Oberoff A, Hoffmeister F, Wirth W. In: Lumb WV.; Jones EW. Veterinary Anesthesia, 3rd ed. Copyring Willians \& Wilkins; 1996. p. 195.

Kuhn USG III, Arko RJ. In: Lumb WV.; Jones EW. Veterinary Anesthesia, 3rd ed. Copyring Willians \& Wilkins; 1996. p. 194.

Lanning CF, Harmel MH. Annu Rev Med 1975; 26:137.

Larsson MHMA, Birgel EH, Benesi FJ. Padrões Hematológicos em Cebus apella anestesiados com ketamina. Braz J. Veterinário. Res. Anim 1999; 36(3). Disponível em: http://www.scielo.br/scielo.php?pid=S1413-95961999000300005\&script=sci_abstract\&tlng=pt

Loomis MR, Henrickson RV, Andson JH. Efeitos do Cloridrato de ketamina no hemograma de macaco rheso (Macaca mulatta). Laboratório Ciência Animal 1980; 30(5):851-3.

Lumb MV, Jones EW. Veterinary Anaesthesia. 3rd ed. Copyring Williams \& Wilkins; 1996.

Martin DP. Guide To The Care and Use of Experimental Animals - Canadia Consil on Animal Care. $1986 ; 2: 25-30$.

Massone F. Anestesia Veterinária: Farmacologia e Técnicas. 5th ed. Rio de Janeiro: Guanabara Koogan; 2008.

Naccarato EF, Hunter WS. Anaesthetic effects of various rations of ketamine and xylazine in rhesus monkeys (Macacca mulatta).Vet Med Small Anim Clin 1979; 
MIRANDA, C.B. et al. Contenção farmacológica em primatas não-humanos com emprego de ketamina e xilazina. Uma revisão bibliográfica. PUBVET, Londrina, V. 5, N. 8, Ed. 155, Art. $1045,2011$.

Novaes AP. In: MASSONE, F. Anestesiologia Veterinária: Farmacologia e Técnicas. 3rd ed. Rio de Janeiro: Guanabara Koogan: 1999. p. 57.

Perumal N, Ramasamy V, Kumar MM, Majumdar SS. Effects of ketamine and thiopentone on serum lipid parameters in adult bonnet monkeys (Macaca radiata). J Am Assoc Lab Anim Sci 2007; 46(3):21-3.

Pert CB, Quirion R. In: Lumb WV.; Jones EW. Veterinary Anesthesia, 3rd ed. Copyring Willians \& Wilkins; 1996. p. 201.

Pulley AC, Roberts JA, Lerche NW. Four preanesthetic oral sedation protocols for rhesus macaques (Macaca mulatta). J Zoo Wildl Med 2004; 35(4):497-502.

Reutlinger RA, Karl AA, Vinal SI. Am J Vet Res 1980; 41:1453.

Rizvi SSR, Altaf S, Naseem AA, Assif M, Rasul Z, Qayyum M. The effects of ketamine hydrochloride anesthesia on basal and $\mathrm{N}$-methyl-D,L-aspartate induced plasma prolactin secretion in the adult male rhesus monkey. 2000, Life Sciences Pharmacology Letters Accelerated Communication

Slikker W Jr, Zou X, Hotchkiss CE, Divine RL, Sadovova N, Twaddle NC, et al. Ketamineinduced neuronal cell death in the perinatal rhesus monkey. Toxicol Sci 2007; 98(1):145-58.

Schmidt H, Fournadjier G, et al. 1970. In: Lumb WV.; Jones EW. Veterinary Anesthesia, 3rd ed. Copyring Willians \& Wilkins; 1996. p. 65.

Springer DA, Baker KC. Effect of ketamine anesthesia on daily food intake in Macaca mulatta and Cercopithecus aethiops. Am J Primatol 2007; 69(10):1080-92.

Tranquilli WJ, Maze M. In: Aantaa R. Alpha 2-adrenoceptor Antagonists. BaillieÁ re's Clinical Anaesthesiology 2000; 14(2):285-92.

Toft P, Rumer U. In: Lumb WV.; Jones EW. Veterinary Anesthesia, 3rd ed. Copyring Willians \& Wilkins; 1996. p. 243.

Venkatesan R, Nagarajan P, Rajaretnam RS, Majumdar SS. Hematologic and serum biochemical values in aged female bonnet macaques (Macaca radiate) anesthetized with ketamine hydrochloride. J Am Assoc Lab Anim Sci 2006; 45(2):45-8.

Winterborn AN, Bates WA, Feng C, Wyatt JD. The efficacy of orally dosed ketamine ande ketamine/medetomidine compared with intramuscular ketamine in rhesus macaques (Macaca mulatta) and the effects of dosing route on haematological stress markers. J Med Primatol $2008 ; 37(3): 116-27$.

White GL, Cummings JF. Vet Med Small Anim Clin 1979; 74:392.

White PF, Way WL, Trevor, AJ. Anesthesiology 1982; 56:119.

Yoshizawa K, Oishi Y, Matsumoto M, Nyska A. Ischemic brain damage after ketamine and xylazine treatment in a young labotatory monkey (Macaca fascicularis). Contemp Top Lab Anim Sci 2005; 44(5):19-24. 